\title{
Microbial contamination of the hands of healthcare providers in the operating theatre of a central hospital
}

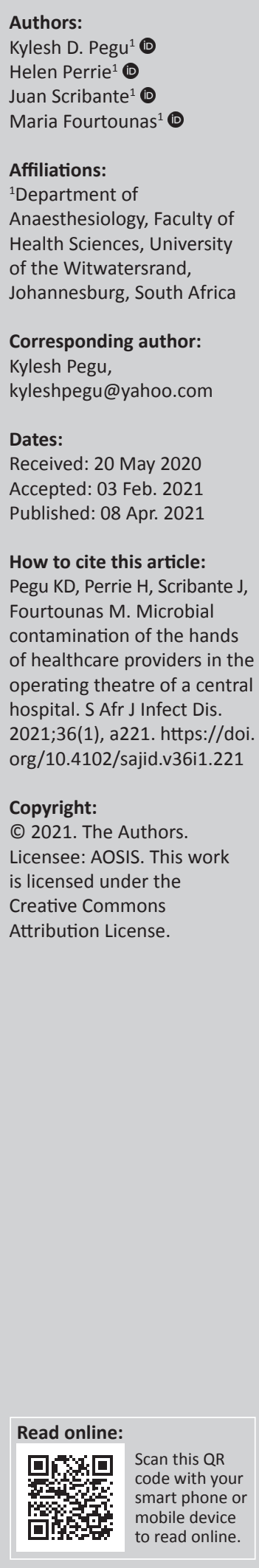

Background: Effort is invested in maintaining the sterility of the operating field, but less attention is paid to potential healthcare associated infection (HAI) sources through patient contact with non-scrubbed healthcare providers (HCPs). A single microbiological assessment of hands can provide a good assessment of the potential dynamic transmission of microorganisms. The aim of this study was to identify and quantify the microbial growth on the hands of HCPs in the operating theatres of Chris Hani Baragwanath Academic Hospital.

Methods: A prospective, contextual and descriptive study design was followed. Seventy-five samples were collected using convenience sampling from an equal number of surgeons, anaesthetists and nurses. Specimens were taken using agar plates and underwent semiquantitative analysis.

Results: All the hands of the HCPs displayed growth; 95\% grew commensals and 64\% grew pathogens. Eighteen commensal microorganisms and 21 pathological microorganisms were noted. Comparisons of commensal, pathological and combined levels of contamination among the three groups were not statistically significant ( $p=0.061, p=0.481, p=0.236$ ). No significant difference between the growth of combined microorganisms $(p=0.634)$ and pathological microorganisms $(p=0.499)$ among the groups. Surgeons had significantly more commensal growth $(p=0.041)$. There was no statistically significant difference between sexes $(p=0.290)$.

Conclusion: It was concerning that $100 \%$ of the hands of HCPs who were about to commence with the surgical list had microbial growth. These HCPs could have already been in contact with patients and equipment in the theatre environment.

Keywords: hands; healthcare providers; commensal; pathogen; microorganism.

\section{Introduction}

Healthcare-associated infections (HAIs) are infections that appear in a patient under medical care that were not present at the time of admission. ${ }^{1}$ The incidence of HAIs in developed countries ranges from $3.5 \%$ to $12 \%$, whilst in developing countries it ranges from $5.7 \%$ to $19.1 \% .^{2}$ Patients who develop an HAI remain in hospital two and a half times longer, with hospital costs nearly three times higher, and incur further medical costs after discharge from hospital when compared to uninfected patients. ${ }^{3}$ The most frequent types of HAI include central line-associated bloodstream infections, catheter-associated urinary tract infections, surgical site infections and ventilatorassociated pneumonia. ${ }^{1}$ The risk factors for developing an HAI include poor hygienic conditions of the healthcare setting, increased patient susceptibility, inadequate hand hygiene and poor knowledge of infection control policies. ${ }^{4}$

In the operating theatre (OT), much effort is invested in maintaining the sterility of the operating field, but less attention is paid to potential HAI sources resulting from patient contact with non-scrubbed healthcare providers (HCPs). ${ }^{5}$ The microorganisms present on the hands of HCPs serve as a reservoir for potential contamination. In the OT, contamination of the hands of HCPs can independently increase the risk of patients being contaminated. ${ }^{6}$

Loftus et al. $^{7}$ conducted a study where the phenotypes of Staphylococcus aureus isolated from HCPs' hands were linked phenotypically to patients' 30-day post-operative cultures. Pathogenic microorganisms cultured from the hands of HCPs include coagulase-negative Staphylococci, Acinetobacter baumannii, Klebsiella pneumoniae, Proteus mirabilis, Enterobacter cloacae, Staphylococcus aureus, Pseudomonas aeruginosa, Escherichia coli and methicillin-resistant Staphylococcus aureus. ${ }^{8}$ The intraoperative environment serves as a risk factor for the development of HAIs. ${ }^{5}$ The failure to conduct hand hygiene measures before and after patient contact can lead 
to contamination of the patient OT equipment, hence creating a reservoir for pathogens that can cross-infect the next patient. ${ }^{5}$ Non-compliance with hand hygiene practices by the non-scrubbed staff has increased microbial transmission to patients in the OT environment. ${ }^{9}$ Contamination of OT equipment such as telephones, keyboards, anaesthesia machines and stopcocks by hands with pathogens has been well documented. ${ }^{5}$ Unhygienic staff perform invasive procedures such as tracheal intubation and insertion of intravascular devices and urinary catheters, which enables pathogens to bypass the normal patient defence barriers and cause HAIs. ${ }^{5}$ The infective dose for many pathogens appears to be very low, and slight contamination of the environment is sufficient to cause infection. ${ }^{10}$

Ineffective hand hygiene is being practised globally. ${ }^{1,2,3,4,5,11}$ The duration of microorganism survival on hands differs with various microorganisms, with some able to survive for more than an hour. ${ }^{10}$ Inadequate hand hygiene often leads to the survival of these microorganisms causing increased risk of cross-transmission. ${ }^{10}$ Hand contamination has increased sequelae beyond the intraoperative risk of transmission. ${ }^{12}$ Directly observed behaviour of hand hygiene has shown low compliance to institutionally developed protocols. ${ }^{5,13}$

A single microbiological assessment of hands can provide a good assessment of the potential transmission. ${ }^{14}$ Limited South African studies reporting hand contamination of HCPs have been identified, either nationally or at Chris Hani Baragwanath Academic Hospital (CHBAH). The aim of this study was to identify and quantify the microbial growth on the hands of HCPs in the OTs of CHBAH.

\section{Methods}

A prospective, contextual and descriptive study design was followed. Approval to conduct the study was obtained from the Human Research Ethics Committee (Medical) and other relevant authorities.

The study population consisted of HCPs (surgeons, anaesthetists and nurses) in the OTs of CHBAH. Convenience sampling was used, and because of financial constraints, 75 samples were collected, which allowed an equal number of participants in each of the three groups. After consultation with a biostatistician, a sample size of 75 participants at an expected contamination rate of $80 \%$ in all HCPs, with an average of $65 \%$ contamination found in the literature, $15,16,17,18,19,20$ will give a power of $84 \%$ at a significance level of $5 \%$. All HCPs who consented to participate in the study were included and were only enrolled once.

In consultation with a microbiologist, it was decided to use a low-budget, high-volume process. Agar plates were used to collect specimens. This form of semi-quantitative analysis is cheap and requires minimal microbiological analysis and logistical support. ${ }^{21}$ Samples were collected on single days over 1 month to prevent HCPs from changing their practices of hand washing. The study was explained to the HCPs, and signed consent was obtained prior to specimen collection. Agar plating was conducted in the morning prior to the commencement of the surgical list. The collection process consisted of HCPs pressing the fingertips of their dominant hand, followed by the base of the same hand, into the agar plate for $5 \mathrm{~s}$ each.

The samples were collected by one author (K.P.), and a standard laboratory request form was used to enter each specimen's differentiating information. The samples collected were stored at room temperature and were delivered to the laboratory at the earliest possible time on the same day. The samples were processed by an accredited laboratory, Vermaak and Partners Pathologists.

The samples were incubated for $48 \mathrm{~h}$, after which the colonies were examined, tallied and detailed. For this study, a standard semi-quantitative criterion was used with assigned scores given to microorganisms:

- $1+=$ rare

- $2+=$ few

- $3+=$ moderate

- $4+=$ many

A distinction between pathological and commensal microorganisms was made; however, this was difficult as some commensal microorganisms can result in a nosocomial infection, and some pathological microorganisms can also be commensals in the appropriate setting. Participants could ask for their microbial results, and if a participant grew pathological organisms, they were informed of the growth.

The data were analysed with Stata version 16 (StataCorp USA). The categorical variables were described using frequencies and percentages. Comparisons between the levels of contamination among the groups were done using Fisher's exact test. The Kruskal-Wallis test was used to compare the number of microorganisms among the three groups. The Dunn test was applied to any significant difference. A $p$-value of $<0.05$ was considered statistically significant.

\section{Results}

Seventy-seven HCPs were approached, but two declined. Samples were collected from 75 participants, which included 25 anaesthetists, 25 surgeons and 25 nurses. Of the participants, $69.3 \%$ were female and $30.7 \%$ were male. Eighteen commensal microorganisms and 21 pathological microorganisms were grown. All hands of the HCPs displayed growth, of which $95 \%$ cultured commensals and $64 \%$ cultured pathogens. No $4+$ growth was noted. A table identifying and quantifying the microorganisms grown is included as supplementary data. Microorganisms were classified with the use of recent literature and with the assistance of a medical microbiologist.

The growth according to sex is shown in Table 1. A $p$-value of 0.290 was calculated, which was not statistically significant, 
TABLE 1: Growth according to sex.

\begin{tabular}{|c|c|c|c|c|c|c|c|c|c|}
\hline \multirow{3}{*}{$\begin{array}{l}\text { Professional } \\
\text { designation }\end{array}$} & \multirow[t]{3}{*}{ Total } & \multirow[t]{3}{*}{ Male } & \multirow[t]{3}{*}{ Female } & \multicolumn{6}{|c|}{ Growth } \\
\hline & & & & \multicolumn{2}{|c|}{ Commensal } & \multicolumn{2}{|c|}{ Pathological } & \multicolumn{2}{|c|}{ Combined } \\
\hline & & & & Male & Female & Male & Female & Male & Female \\
\hline Anaesthetist & 25 & 8 & 17 & 3 & 6 & 0 & 0 & 5 & 11 \\
\hline Nurse & 25 & 0 & 25 & 0 & 8 & 0 & 3 & 0 & 14 \\
\hline Surgeon & 25 & 15 & 10 & 6 & 6 & 1 & 0 & 8 & 4 \\
\hline Total & 75 & 23 & 52 & 9 & 20 & 1 & 3 & 13 & 29 \\
\hline
\end{tabular}

TABLE 2: Number of organisms on healthcare provider hands.

\begin{tabular}{lcc}
\hline Number of organisms & Number of HCPs & HCPs (\%) \\
\hline 1 & 18 & 24.0 \\
2 & 30 & 40.0 \\
3 & 20 & 26.7 \\
4 & 3 & 4.0 \\
5 & 2 & 2.7 \\
6 & 2 & 2.7 \\
\hline
\end{tabular}

HCPs, healthcare providers.

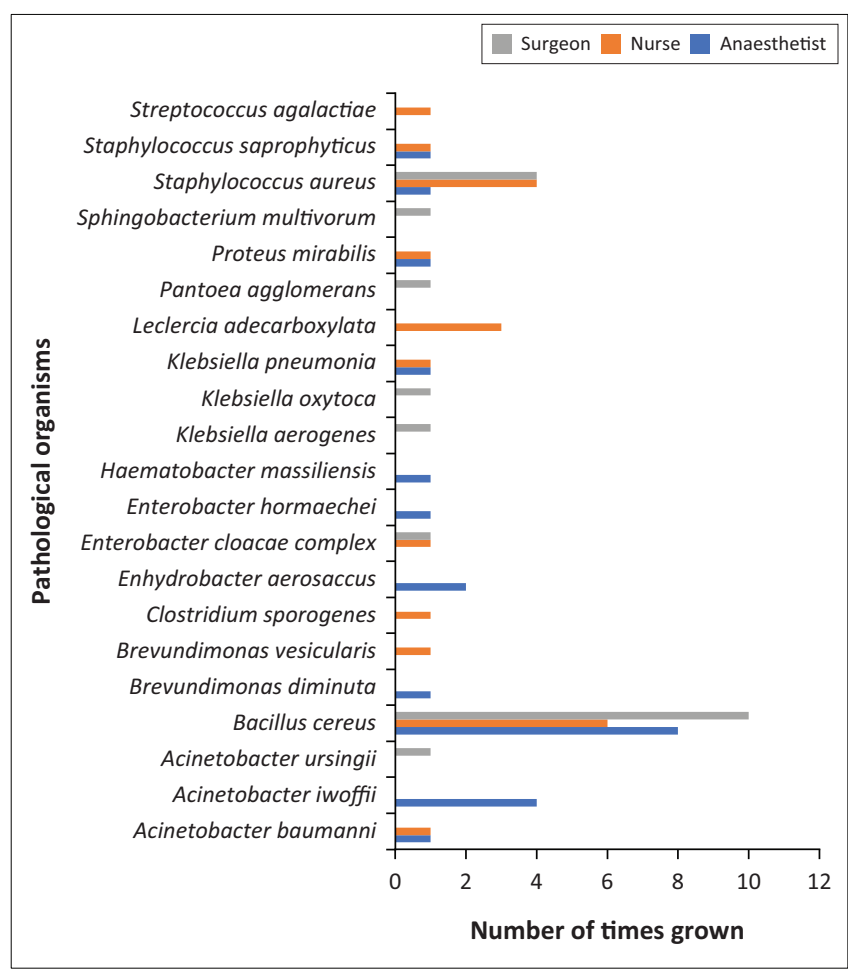

FIGURE 1: Pathological growth amongst each group of healthcare workers.

for commensal, pathological and combined growth between the two sexes.

The number of microorganisms cultured on the hands of HCPs is shown in Table 2. Seventy-six per cent of HCPs had two or more microorganisms on their hands.

Figure 1 shows the pathological microorganisms and the number of times each was grown by each type of HCP.

Figure 2 shows the commensal microorganisms and the number of times they were grown amongst each group of HCPs.

The levels of contamination of microorganisms on the hands between the three groups of HCPs were compared. There

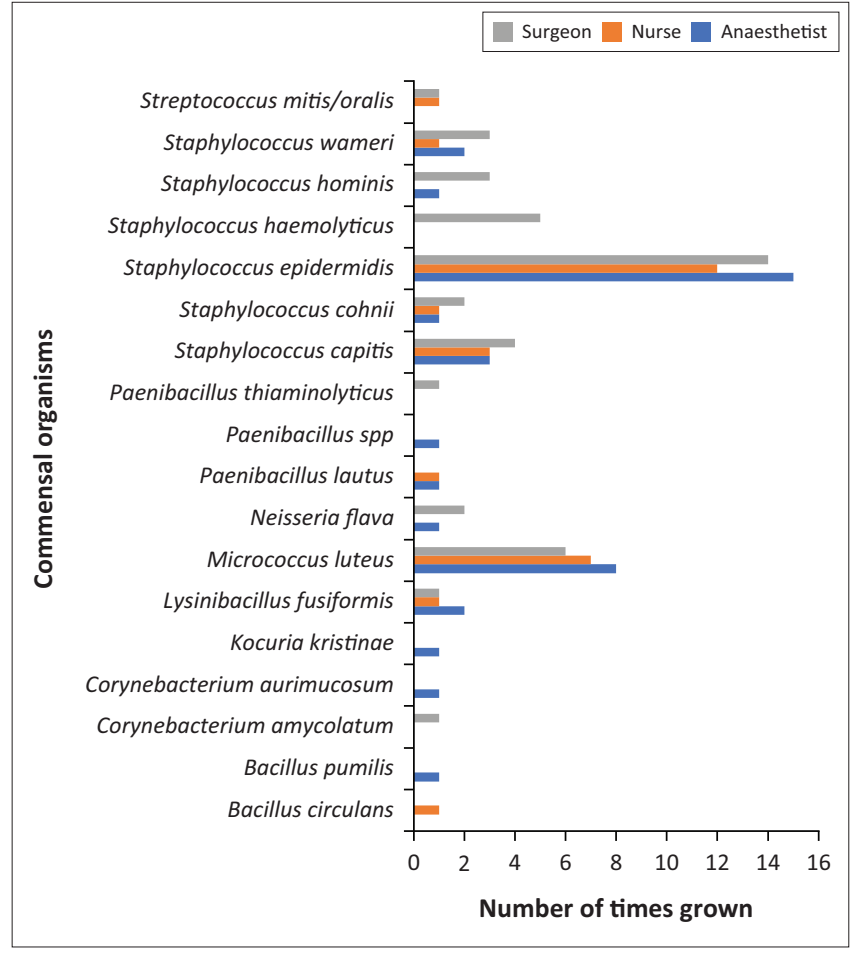

FIGURE 2: Commensal growth among each group.

were no significant differences found when combined $(p=0.061)$, commensal $(p=0.481)$ and pathological $(p=0.236)$ microorganisms were compared.

The number of microorganisms on the hands of HCPs in each group were compared. There was a significant difference in the growth of commensals between the groups $(p=0.041)$. A significant difference was present between nurses and surgeons $(p=0.009)$ and anaesthetists and surgeons $(p=0.052)$. The surgeons had the highest number of commensal microorganisms on their hands. There was no significant difference between the groups in the growth of pathological microorganisms $(p=0.499)$ and combined microorganisms $(p=0.634)$.

\section{Discussion}

This study emphasises a significant level of microorganism contamination on the hands of HCPs; all the hands of the participants were contaminated, with $76 \%$ of the hands growing two or more microorganisms. A study in Wales by Al-Allak et al. ${ }^{22}$ found that $100 \%$ of HCPs' hands were contaminated. Hand contamination ranged from $62.3 \%$ to $100 \%$ in studies conducted in various hospital settings in developed and developing countries. ${ }^{17,20,23,24,25,26,27,28}$ It is of 
concern that in our study, all participants were about to commence with the surgical list for that day and had already been in contact with the OT environment.

Commensal microorganisms were cultured in $95 \%$ of participants. Eighteen commensal microorganisms were cultured, with the most predominant being Staphylococcus epidermis $(54.7 \%)$, Bacillus cereus (32\%), Micrococcus luteus (28\%) and Staphylococcus capitis (13.3\%). Staphylococcus epidermidis may promote sepsis by its ability to form biofilms on indwelling medical devices and produce toxins. ${ }^{29}$ Bacillus cereus can cause localised infection and bacteraemia and can be associated with haematogenous spread..$^{30}$ In haematological patients Bacillus cereus has the ability to invade the central nervous system..$^{30}$ Micrococcus luteus has been implicated in HAIs in immunocompromised patients. ${ }^{31}$ Staphylococcus capitis can be considered a pathogen in neonates, and a drugresistant form has emerged as a cause of sepsis in neonatal intensive care units. ${ }^{32}$ The microorganisms grown in our study are in keeping with commensal strains. ${ }^{33}$ Commensal microorganisms may cause infection if they enter a sterile body cavity, ${ }^{34}$ may permanently colonise the hands of HCPs and are often associated with HAIs. ${ }^{35}$

Pathological microorganisms were cultured in $64 \%$ of participants. Twenty-one pathological organisms were grown, with the most predominant being Staphylococcus aureus (12\%), Acinetobacter iwoffii (5.3\%) and Leclercia adecarboxylata (4\%). Staphylococcus aureus has the propensity to develop resistance to antimicrobial agents and is one of the most lethal bloodstream pathogens. ${ }^{36}$ Acinetobacter iwoffii can cause HAIs in patients with chronic illnesses andincreases the length of hospitalisation and mortality. ${ }^{37}$ Leclercia adecarboxylata commonly affects immunocompromised individuals, and whilst being susceptible to antibiotics, resistant strains have now been identified. ${ }^{38}$

Thirty-nine microorganisms were cultured in total. The microorganism count was more than in other studies; Rocha et al. ${ }^{39}$ grew 11 microorganisms, Wong et al. ${ }^{17}$ grew 20 microorganisms, Sureshkumar et al. ${ }^{27}$ grew 12 microorganisms and Larson $^{40}$ grew 14 microorganisms. Possible reasons for microorganism growth could be ineffective hand hygiene, damaged skin and the local healthcare microbial environment. . $139,40,41^{2}$

There was no significant difference between the level of growth of microorganisms on the hands of anaesthetists, nurses and surgeons. No differences were noted between professional designations in prior studies, indicating that this does not influence the microbial environment of hands. ${ }^{16,20,42}$ When comparing the number of microorganisms present on the hands of HCPs, there was no significant difference for combined and pathological growth. The surgeons' hands had a higher number of commensal microorganisms present when compared to anaesthetists and nurses. The surgeons are possibly exposed to a different microbial environment by performing work in wards prior to arriving in theatre.
Of the studies assessing the hand hygiene of anaesthetists, only two gave total growth values that ranged from $66 \%$ to $71 \%{ }^{43,44}$ Anaesthetists in this study had a $100 \%$ growth rate from their hands whilst growing more microorganisms. The $100 \%$ growth rate from the hands of nurses was higher than the growth rates identified in two studies, ranging from 5.1\% to $77.5 \%{ }^{40,45}$ The growth from this study was in keeping with studies assessing damaged skin and poor nail hygiene. ${ }^{40,45}$ There were no specific studies identified that assessed the hand hygiene of only surgeons in the OT environment.

The population was skewed with regard to sex, as $69.3 \%$ females and $30.7 \%$ males participated in the study. However, there was no statistically significant difference between the sexes. No study was identified that showed differences with microorganisms between males and females. The analysis was done because of females possibly having longer nails, nail polish and more rings when compared to males. This was not further analysed as this was not an objective of the study.

The results from this study indicate the need for adequate hand hygiene practice. A simple hand hygiene model, such as 'My Five Moments of Hand Hygiene', has had low compliance in healthcare settings. ${ }^{46,47}$

Altering poor hand hygiene practice requires a multidimensional model targeting knowledge, attitude and clinical skills. ${ }^{48}$ Elective hand hygiene is difficult to correct and will be challenging to adjust to an implemented guideline ${ }^{49}$ Barriers to hand hygiene, which are similar in our healthcare setting, are high workloads, too few personnel, unfavourable hand hygiene materials and structures and high infection risk activities. ${ }^{48}$ Limitations of this study included a contextual analysis of the microorganisms present. The funding of the study was a limitation because a semiquantitative analysis was done; however, a single microbiological assessment of hands can provide a good assessment of the potential transmission. The pandemic caused by severe acute respiratory syndrome coronavirus 2 (SARS-CoV-2) has emphasised the need for compliance with hand hygiene measures.

\section{Conclusion}

It was concerning that $100 \%$ of the hands of HCPs who were about to commence with the surgical list had microbial growth. These HCPs could have already been in contact with patients and equipment in the theatre environment. Microorganisms cultured on hands are a source of crosstransmission, which may result in HAIs. Institutions require the implementation of a multidimensional model to amend and implement guidelines and to increase the awareness and availability of hand hygiene materials.

\section{Acknowledgements}

This research was done in partial fulfilment of a Master of Medicine degree. 


\section{Competing interests}

The authors declare that they have no financial or personal relationships that may have inappropriately influenced them in writing this article.

\section{Authors' contributions}

K.D.P., H.P., J.S. and M.F. contributed equally to this article.

\section{Ethical considerations}

Approval to conduct the study was obtained from the WITS Human Research Ethics Committee (Medical), ethical clearance number M180603.

\section{Funding information}

Funding was provided by the Department of Anaesthesiology of Chris Hani Baragwanath Academic Hospital.

\section{Data availability}

The data that support the findings of this study are available from the corresponding author, K.P., upon reasonable request.

\section{Disclaimer}

The views and opinions expressed in this article are those of the authors and do not necessarily reflect the official policy or position of any affiliated agency of the authors.

\section{References}

1. Khan HA, Baig FK, Mehboob R. Nosocomial infections: Epidemiology, prevention control and surveillance. Asian Pac J Trop Biomed. 2017;7(5):478-482. https:// doi.org/10.1016/j.apjtb.2017.01.019

2. Bagheri Nejad S, Allegranzi B, Syed SB, Ellis B, Pittet D. Health-care-associated infection in Africa: A systematic review. Bull World Health Organ. 2011;89(10): 757-765. https://doi.org/10.2471/BLT.11.088179

3. Plowman R. The socioeconomic burden of hospital acquired infection. Euro Surveill. 2000;5(4):49-50. https://doi.org/10.2807/esm.05.04.00004-en

4. Wattal C, Khardori N. Current practices for infection prevention in the hospital settings. In: Wattal C, Khardori N, editors. Hospital infection prevention: Principles and practices. Volume 1. 1st ed. New Delhi: Springer, 2014; p. 45-51.

5. Krediet AC, Kalkman CJ, Bonten MJ, Gigengack AC, Barach P. Hand-hygiene practices in the operating theatre: An observational study. $\mathrm{Br} J$ Anaesth 2011;107(4):553-558. https://doi.org/10.1093/bja/aer162

6. Loftus RW, Koff MD, Brown JR, et al. The dynamics of Enterococcus transmission from bacterial reservoirs commonly encountered by anesthesia providers. Anesth Analg. 2015;120(4):827-836. https://doi.org/10.1213/ANE.0000000000000123

7. Loftus RW, Koff MD, Brown JR, et al. The epidemiology of Staphylococcus aureus transmission in the anesthesia work area. Anesth Analg. 2015;120(4):807-818 https://doi.org/10.1213/ANE.0b013e3182a8c16a

8. WHO guidelines on hand hygiene in health care: First global patient safety challenge clean care is safer care [homepage on the Internet]. Geneva: World Health Organization; 2009 [updated 2018 May 23; cited 2019 Oct 22]. Available from: https://www.ncbi.nlm.nih.gov/books/NBK144013

9. Dallolio L, Raggi A, Sanna T, et al. Surveillance of environmental and procedural measures of infection control in the operating theatre setting. Int J Environ Res Public Health. 2017;15(1):46. https://doi.org/10.3390/ijerph15010046

10. La Fauci V, Genovese C, Facciola A, Palamara MAR, Squeri R. Five-yea microbiological monitoring of wards and operating theatres in southern Italy. J Prev Med Hyg [serial online]. 2017 [cited 2019 Sep 21];58(2):E166-E172. Available from: https://www.researchgate.net/publication/319693718_Fiveyear microbiological monitoring of wards and operating theatres in year_microbio
southern Italy

11. Kissoon N, Carcillo JA, Espinosa V, et al. World federation of pediatric intensive care and critical care societies: Global sepsis initiative. Pediatr Crit Care Med. 2011;12(5):494-503. https://doi.org/10.1097/PCC.0b013e318207096c
12. Martin LD, Rampersad SE, Geiduschek JM, Zerr DM, Weiss GK, Martin LD. Modification of anesthesia practice reduces catheter-associated bloodstream infections: A quality improvement initiative. Paediatr Anaesth. 2013;23(7): infections: A quality improvement initiative.
588-596. https://doi.org/10.1111/pan.12165

13. Rowlands J, Yeager MP, Beach M, Patel HM, Huysman BC, Loftus RW. Video observation to map hand contact and bacterial transmission in operating rooms. Am J Infect Control. 2014;42(7):698-701. https://doi.org/10.1016/j. ajic.2014.02.021

14. Loftus RW, Brown JR, Patel HM, et al. Transmission dynamics of gram-negative bacterial pathogens in the anesthesia work area. Anesth Analg. 2015;120(4): 819-826. https://doi.org/10.1213/ANE.0000000000000626

15. Jeske HC, Tiefenthaler W, Hohlrieder M, Hinterberger G, Benzer A. Bacteria contamination of anaesthetists' hands by personal mobile phone and fixed phone use in the operating theatre. Anaesthesia. 2007;62(9):904-906. https://doi. org/10.1111/j.1365-2044.2007.05172.x

16. Visalachy S, Palraj KK, Kopula SS, Sekar U. Carriage of multidrug resistant bacteria on frequently contacted surfaces and hands of health care workers. J Clin Diagn Res. 2016;10(5):DC18-DC20. https://doi.org/10.7860/JCDR/2016/19692.777

17. Wong JL, Siti Azrin AH, Narizan MI, et al. Back to basic: Bio-burden on hands of health care personnel in tertiary teaching hospital in Malaysia. Trop Biomed [serial online]. 2014 [cited 2019 Sep 1];31(3):534-539. Available from: http:// [serial online]. 2014 [cited 2019 Sep 1];31(3):534-51
www.msptm.org/files/534_-_539_Siti_Asma_H.pdf

18. Istenes N, Bingham J, Hazelett S, Fleming E, Kirk J. Patients' potential role in the transmission of health care-associated infections: Prevalence of contamination with bacterial pathogens and patient attitudes toward hand hygiene. Am J Infect Control. 2013;41(9):793-798. https://doi.org/10.1016/j.ajic.2012.11.012

19. Forer Y, Block C, Frenkel S. Preoperative hand decontamination in ophthalmic surgery: A comparison of the removal of bacteria from surgeons' hands by routine antimicrobial scrub versus an alcoholic hand rub. Curr Eye Res. 2017;42(9):1333-1337. https://doi.org/10.1080/02713683.2017.1304559

20. Chaka T, Milisa G, W Feye B, Kassa R. Bacterial isolates from cell phones and hands of health care workers: A cross sectional study in pediatric wards at Black Lion Hospital, Addis Ababa, Ethiopia. Int J Biochem Physiol. 2016;7(4):288-294. https://doi.org/10.4172/2155-9597.1000288

21. Devamani C, Norman G, Schmidt WP. A simple microbiological tool to evaluate the effect of environmental health interventions on hand contamination. Int Environ Res Public Health. 2014;11(11):11846-11859. https://doi.org/10.3390/ ijerph111111846

22. Al-Allak A, Sarasin S, Key S, Morris-Stiff $G$. Wedding rings are not a significant source of bacterial contamination following surgical scrubbing. Ann R Coll Surg Engl. 2008;90(2):133-135. https://doi.org/10.1308/003588408X242051

23. Fagernes $M$, Lingaas $E$. Factors interfering with the microflora on hands: $A$ regression analysis of samples from 465 healthcare workers. J Adv Nurs. 2011;67(2):297-307. https://doi.org/10.1111/j.1365-2648.2010.05462.x

24. Longtin Y, Schneider A, Tschopp C, et al. Contamination of stethoscopes and physicians' hands after a physical examination. Mayo Clin Proc. 2014;89(3): 291-299. https://doi.org/10.1016/j.mayocp.2013.11.016

25. Sasahara T, Ae R, Watanabe M, et al. Contamination of healthcare workers' hands with bacterial spores. J Infect Chemother. 2016;22(8):521-525. https://doi. org/10.1016/j.jiac.2016.04.007

26. Sarfraz A, Bhattacharyya $S$, Aftab M, et al. A study on microbial flora on skin of health care providers in a tertiary care hospital in Southern India. J Clin Diagn Res. 2015;12(11):9-11. https://doi.org/10.14260/jemds/2015/672

27. Sureshkumar M, Suriyapraba R, Priyadharsini R. A study on microbial flora on skin of health care providers in a tertiary care hospital in southern India. J Clin Diagn Res. 2018;12(11):9-11. https://doi.org/10.7860/JCDR/2018/37717.12266

28. Senthil S, Hegde A, Kulkarni V, Manipura R. Bacterial contamination of hands of medical interns and undergraduate students. Asian J Pharm Clin Res. 2017;10(12):145-149. https://doi.org/10.22159/ajpcr.2017.v10i12.20908

29. Otto M. Staphylococcus epidermidis: A major player in bacterial sepsis? Future Microbiol. 2017;12(12):1031-1033. https://doi.org/10.2217/fmb-2017-0143

30. Tusgul S, Prod'hom G, Senn L, Meuli R, Bochud PY, Giulieri SG. Bacillus cereus bacteraemia: Comparison between haematologic and nonhaematologic patients. New Microbes New Infect. 2016;15:65-71. https://doi.org/10.1016/j. nmni.2016.11.011

31. Oudiz RJ, Widlitz A, Beckmann XJ, et al. Micrococcus-associated central venous catheter infection in patients with pulmonary arterial hypertension. Chest. 2004;126(1):90-94. https://doi.org/10.1378/chest.126.1.90

32. Laurent F, Butin M. Staphylococcus capitis and NRCS-A clone: The story of an unrecognized pathogen in neonatal intensive care units. Clin Microbiol Infect. 2019;25(9):1081-1085. https://doi.org/10.1016/j.cmi.2019.03.009

33. Elsner P. Antimicrobials and the skin physiological and pathological flora. Curr Probl Dermatol. 2006;33:35-41. https://doi.org/10.1159/000093929

34. Rosenthal M, Aiello A, Larson E, Chenoweth C, Foxman B. Healthcare workers' hand microbiome may mediate carriage of hospital pathogens. Pathogens. 2013;3(1):1-13. https://doi.org/10.3390/pathogens3010001

35. Kampf G, Kramer A. Epidemiologic background of hand hygiene and evaluation of the most important agents for scrubs and rubs. Clin Microbiol Rev. 2004;17(4):863-893. https://doi.org/10.1128/CMR.17.4.863-893.2004

36. Paulsen J, Mehl A, Askim Å, Solligård E, Åsvold BO, Damås JK. Epidemiology and outcome of Staphylococcus aureus bloodstream infection and sepsis in a Norwegian county 1996-2011: An observational study. BMC Infect Dis. 2015;15:116-117. https://doi.org/10.1186/s12879-015-0849-4

37. Tas MY, Oguz MM, Ceri M. Acinetobacter iwoffii peritonitis in a patient on automated peritoneal dialysis: A case report and review of the literature. Case Rep Nephrol. 2017;2017:5760254. https://doi.org/10.1155/2017/5760254 
38. Matsuura H, Sugiyama S. Sepsis and Leclercia adecarboxylata. QJM: Int J Med. 2018;111(10):733-734. https://doi.org/10.1093/qjmed/hcy131

39. Rocha LA, Ferreira de Almeida EBL, Gontijo Filho PP. Changes in hands microbiota associated with skin damage because of hand hygiene procedures on the health care workers. Am J Infect Control. 2009;37(2):155-159. https://doi.org/10.1016/j. ajic.2008.04.251

40. Larson EL, Hughes CA, Pyrek JD, Sparks SM, Cagatay EU, Bartkus JM. Changes in bacterial flora associated with skin damage on hands of health care personnel. Am J Infect Control. 1998;26(5):513-521. https://doi.org/10.1016/S0196-6553(98) 70025-2

41. Fierer N, Hamady M, Lauber CL, Knight R. The influence of sex, handedness, and washing on the diversity of hand surface bacteria. Proc Natl Acad Sci USA. 2008;105(46):17994. https://doi.org/10.1073/pnas.0807920105

42. Khodavaisy S, Nabili M, Davari B, Vahedi M. Evaluation of bacterial and fungal contamination in the health care workers' hands and rings in the intensive care unit. J Prev Med Hyg [serial online]. 2011 [cited 2019 Sep 1];52(4):215-218. Available from: https://pdfs.semanticscholar.org/4d0f/113eb52fb0c4b24f777e 3 4de7c3f7878d409.pdf

43. Gunasekara T, Kudavidanage BP, Peelawattage MK, et al. Bacterial contamination of anaesthetists hands, personal mobile phones and wrist watches used durin theatre sessions. Sri Lankan J Anaesthesiol. 2009;17(1):11-15. https://doi. org/10.4038/slja.v17i1.409
44. Loftus RW, Muffly MK, Brown JR, et al. Hand contamination of anesthesia providers is an important risk factor for intraoperative bacterial transmission. Anesth Analg. 2011;112(1):98-105. https://doi.org/10.1213/ANE.0b013e3181e7ce18

45. Walaszek MZ, Kolpa M, Rozanska A, Jagiencarz-Starzec B, Wolak Z, WojkowskaMach J. Nail microbial colonization following hand disinfection: A qualitative pilot study. J Hosp Infect. 2018;100(2):207-210. https://doi.org/10.1016/j. jhin.2018.06.023

46. Fernandez PG, Loftus RW, Dodds TM, et al. Hand hygiene knowledge and perceptions among anesthesia providers. Anesth Analg. 2015;120(4):837-843. https://doi.org/10.1213/ANE.0000000000000408

47. Zakeri H, Ahmadi F, Rafeemanesh E, Saleh LA. The knowledge of hand hygiene among the healthcare workers of two teaching hospitals in Mashhad. Electron Physician. 2017;9(8):5159-5165. https://doi.org/10.19082/5159

48. Gartmeier M, Baumgartner M, Burgkart R, Heiniger S, Berberat PO. Why hand hygiene is not sufficient: Modeling hygiene competence of clinical staff as a basis for its development and assessment. GMS J Med Educ. 2019;36(4):1-21. https:// doi.org/10.3205/zma001247

49. Contzen N, Inauen J. Social-cognitive factors mediating intervention effects on handwashing: A longitudinal study. J Behav Med. 2015;38(6):956-969. https:// doi.org/10.1007/s10865-015-9661-2 


\section{Appendix 1}

TABLE 1-A1: Identity and quantity of organisms grown.

\begin{tabular}{|c|c|c|c|c|}
\hline \multirow[t]{2}{*}{ Organism } & \multirow[t]{2}{*}{ No of times grown (\%) } & \multicolumn{3}{|c|}{ Level of growth } \\
\hline & & $1+$ & $2+$ & $3+$ \\
\hline \multicolumn{5}{|l|}{ Commensal organisms } \\
\hline Bacillus cereus & $24(32)$ & 16 & 7 & 1 \\
\hline Bacillus pumilis & $1(1.3)$ & 1 & 0 & 0 \\
\hline Corynebacterium amycolatum & $1(1.3)$ & 1 & 0 & 0 \\
\hline Corynebacterium aurimucosum & $1(1.3)$ & 0 & 1 & 0 \\
\hline Kocuria kristinae & $1(1.3)$ & 1 & 0 & 0 \\
\hline Lysinibacillus fusiformis & $4(5.3)$ & 3 & 1 & 0 \\
\hline Micrococcus luteus & $21(28)$ & 6 & 12 & 3 \\
\hline Neisseria flava & $3(4.0)$ & 2 & 1 & 0 \\
\hline Paenibacillus lautus & $2(2.7)$ & 2 & 0 & 0 \\
\hline Paenibacillus spp & $1(1.3)$ & 1 & 0 & 0 \\
\hline Paenibacillus thiaminolyticus & $1(1.3)$ & 1 & 0 & 0 \\
\hline Staphylococcus capitis & $10(13.3)$ & 5 & 4 & 1 \\
\hline Staphylococcus cohnii & $4(5.3)$ & 1 & 2 & 1 \\
\hline Staphylococcus epidermidis & $41(54.7)$ & 22 & 17 & 2 \\
\hline Staphylococcus haemolyticus & $5(6.6)$ & 1 & 3 & 1 \\
\hline Staphylococcus hominis & $4(5.3)$ & 2 & 2 & 0 \\
\hline Staphylococcus wameri & $6(8.0)$ & 5 & 1 & 0 \\
\hline Streptococcus mitis/oralis & $2(2.7)$ & 1 & 1 & 0 \\
\hline \multicolumn{5}{|l|}{ Pathological organisms } \\
\hline Acinetobacter baumanni & $2(2.7)$ & 1 & 1 & 0 \\
\hline Acinetobacter iwoffii & $4(5.3)$ & 4 & 0 & 0 \\
\hline Acinetobacter ursingii & $1(1.3)$ & 0 & 1 & 0 \\
\hline Bacillus circulans & $1(1.3)$ & 1 & 0 & 0 \\
\hline Brevundimonas diminuta & $1(1.3)$ & 0 & 1 & 0 \\
\hline Brevundimonas vesicularis & $1(1.3)$ & 0 & 1 & 0 \\
\hline Clostridium sporogenes & $1(1.3)$ & 1 & 0 & 0 \\
\hline Enhydrobacter aerosaccus & $2(2.7)$ & 2 & 0 & 0 \\
\hline Enterobacter cloacae complex & $2(2.7)$ & 0 & 2 & 0 \\
\hline Enterobacter hormaechei & $1(1.3)$ & 0 & 1 & 0 \\
\hline Haematobacter massiliensis & $1(1.3)$ & 0 & 1 & 0 \\
\hline Klebsiella aerogenes & $1(1.3)$ & 1 & 0 & 0 \\
\hline Klebsiella oxytoca & $1(1.3)$ & 0 & 1 & 0 \\
\hline Klebsiella pneumonia & $2(2.7)$ & 0 & 2 & 0 \\
\hline Leclercia adecarboxylata & $3(4.0)$ & 0 & 1 & 2 \\
\hline Pantoea agglomerans & $1(1.3)$ & 0 & 1 & 0 \\
\hline Proteus mirabilis & $2(2.7)$ & 1 & 1 & 0 \\
\hline Sphingobacterium multivorum & $1(1.3)$ & 0 & 1 & 0 \\
\hline Staphylococcus aureus & $9(12)$ & 5 & 3 & 1 \\
\hline Staphylococcus saprophyticus & $2(2.7)$ & 0 & 1 & 1 \\
\hline Streptococcus agalactiae & $1(1.3)$ & 1 & 0 & 0 \\
\hline
\end{tabular}

